\title{
Optimized Expression of a Hyperthermostable Endoglucanase from Pyrococcus horikoshii in Arabidopsis thaliana
}

\author{
Xia Li, Xiaoyan Geng, Lu Gao, Yanfang Wu, Yongli Wang, Alei Geng, Jianzhong Sun,* \\ and Jianxiong Jiang *
}

\begin{abstract}
Manufacturing microbial cellulase in plants is an attractive strategy for the cost-effective production of cellulosic ethanol, especially the expression of thermostable cellulase, which causes no negative effects on plant growth and development. The beta-1,4-endogenous cellulase from Pyrococcus horikoshii (EGPh) is considered one of the most promising glycosyl hydrolase in the biofuel and textile industry for its hyperthermostability and its capability to hydrolyze crystalline celluloses, which has been researched extensively during recent years. In this study, the coding sequence of EGPh was expressed in Arabidopsis thaliana under the control of a CaMV35S promoter after codon optimization, with the addition of a eukaryotic Kozak sequence. The expression of EGPh caused no deleterious effects to the growth and development of transgenic $A$. thaliana. The heterologous EGPh showed relatively high activities, up to

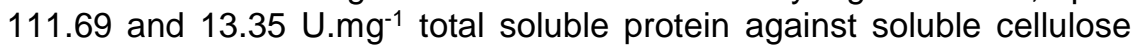
carboxymethyl cellulose (CMC) and insoluble microcrystalline cellulose (Avicel), respectively. The subcellular localization analysis showed that the EGPh protein was targeted to the plasma membrane and cell wall. Based on these results, it is proposed that EGPh is an ideal candidate for the commercial production of hyperthermostable endoglucanase using plants as biofactories.
\end{abstract}

Keywords: Heterologous expression; Hyperthermostable endoglucanase; Arabidopsis thaliana;

Subcellular localization

Contact information: Biofuels Institute, School of the Environment and Safety Engineering, Jiangsu University, 301 Xuefu Road, Zhenjiang 212013, Jiangsu, China;

*Corresponding authors: jxjiang2002@ujs.edu.cn; jzsun1002@ujs.edu.cn

\section{INTRODUCTION}

Lignocellulose is the most abundant material on the earth. The annual yield of lignocellulose is estimated to be 150 to $170 \times 10^{9}$ tons, accounting for $70 \%$ of the global biomass production (Duchesne and Larson 1989; Poorter and Villar 1997; Pauly and Keegstra 2008). Therefore, the production of renewable liquid biofuels, such as ethanol, butanol, or other fermentative products from lignocellulose, has the advantages of a rich raw material, not competing with land use and food supply, as the first generation of biomass has done in the past. According to a report by the U.S. Department of Energy (DOE) and the U.S. Department of Agriculture (USDA), the production of lignocellulosic ethanol will reach 30\% of liquid fuel by 2050 (Chen and Peng 2014). However, with current technologies, the cost for bioconversion of lignocellulose to ethanol remains high. The major barriers are the high cost of the transportation of feedstocks, the thermochemical pretreatment to make the cellulose more accessible to the cellulolytic enzymes, 
as well as a huge requirement of microbial-derived cellulases during the hydrolysis of cellulose (Devaiah et al. 2013; Singh et al. 2015). In such processes, cellulases account for $20 \%$ of the total cost of cellulosic ethanol (Phitsuwan et al. 2012). Therefore, cost-effective production methods of cellulolytic enzymes must be explored.

Plants were proposed as excellent bioreactors for manufacturing a large amount of cellulases at a low cost. It was reported that the cost of enzymes produced from plants was 3- to 70-fold lower than those from other production systems (Menkhaus et al. 2004). Moreover, plant biofactories can offer several other advantages including eukaryotic posttranscriptional modification, easy to control scale of production, and easy collection and storage (Twyman et al. 2003; Sharma and Sharma 2009). Expressing cellulase in lignocellulosic feedstock has become especially favorable, which provides the potential for the feedstock to play a dual role as both the biomass substrate and the enzyme provider. In recent years, a lot of progress has been made in this field. Three main enzymes for lignocellulose degradation, cellulases, hemicellulases, and lignin enzymes are successfully expressed in maize (Devaiah et al. 2013), Arabidopsis (Zeigler et al. 2000), rice (Chou et al. 2011), and tobacco (Gray et al. 2008). However, the expression of mesophilic cellulases causes deleterious effects on plant growth via cell-wall degradation at normal temperature, showing reduced growth, stunted growth, or reduced fertility (Gray et al. 2011; Klose et al. 2013). One strategy to prevent these harmful effects is the expression of thermostable cellulases with an optimal temperature over $60{ }^{\circ} \mathrm{C}$, which is not active during plant growth (Jiang and Li 2009) and then the enzyme activity might be activated at a high temperature during post-harvesting treatments. Moreover, thermostable cellulases would benefit the industrial process of biomass degradation by eliminating bacterial contamination, and increasing the reaction rate and substrate solubility when the enzymatic hydrolysis was performed at high temperatures (Haki and Rakshit 2003; Kishishita et al. 2015). Thermostable cellulases from Acidothermus cellulolyticus and Thermomonospora fusca have been expressed in various plant species with no harmful effects and showed simplified processing and reduced exogenous enzyme loading in cellulosic ethanol production (Ziegler et al. 2000; Ransom et al. 2007; Chou et al. 2011)

The hyperthermophilic beta-1,4-endogenous cellulase (EC 3.2.1.4) (EGPh; glycosyl hydrolase family 5) was identified from Pyrococcus horikoshii, which is the first hyperthermostable endoglucanase to which celluloses are the best substrates, including Avicel, carboxymethyl cellulose (CMC), and $\beta$-glucose oligomers (Ando et al. 2002). With strong hydrolysis activity toward crystalline celluloses, the optimum reaction temperature at $95{ }^{\circ} \mathrm{C}$, and its ability to hydrolyze cellulose completely to glucose at high temperature in combination with the hyperthermophilic $\beta$-glucosidase (EC 3.2.1.21) from Pyrococcus furiosus, this enzyme was considered an ideal candidate for the industrial hydrolysis of cellulose (Kashima et al. 2005; Kim and Ishikawa 2010a). Therefore, it has been extensively researched in recent years. Its crystal structure was determined in a previous study (Kim and Ishikawa 2010b). Then, the relationship between its function and crystal structure was studied (Yang et al. 2012; Kim and Ishikawa 2013). This endocellulase was successfully produced with over $100 \mathrm{mg} / \mathrm{L}$ by fungus Talaromyces cellulolyticus, which was the first step for the industrial scale production of EGPh (Biswas et al. 2006).

The objective of this research was to test the effects of expressing EGPh in biomass crops on reducing cellulase loading during the pretreatment process to reduce the bioconversion cost of lignocellulose to ethanol. To achieve a high expression level, the codon optimization was conducted, and the Kozak sequence was added immediately preceding the AUG codon. The enzyme activity, the subcellular localization of the 
recombinant $\mathrm{EGPh}$, and the phenotype of the transgenic plants were analyzed to evaluate the application prospect of heterologous EGPh in industry.

\section{EXPERIMENTAL}

\section{Materials}

Arabidopsis thaliana wild-type Columbia (Col-0) and Agrobacterium tumefaciens EHA105 were preserved in the authors' lab (Zhenjiang China). The plant expression vector pBI121 was given by the Nanjing Forestry University (Nanjing, China). The Taq DNA polymerase, T4 DNA ligase, and the DNA extraction kit were purchased from Takara Biotechnology Co., Ltd. (Dalian, China).

\section{Methods}

Codon optimization and gene synthesis

The coding sequence of the hyperthermostable $\beta$-1,4- endonuclease EGPh gene (Gene ID: PH1171) of P. horikoshii was optimized based on Sorghum bicolor codon usage via the OptimumGene ${ }^{\mathrm{TM}}$ algorithms codon optimization technology (GenScript Co., Ltd., Nanjing, China). The Kozak sequence ACCACC was added immediately preceding the initiator codon ATG of the optimized sequence. The XbaI and SmaI restriction sites were added at the 5' and 3' ends, respectively. The whole sequence was synthesized via GenScript Co., Ltd. (Nanjing, China) and cloned into the pUC57 plasmid.

Construction of expression vectors and transformation into A. thaliana

After verification by sequencing, the plasmids pUC57-EGPh were digested with $X b a I$ and SmaI. Then, the EGPh coding sequence was cloned into pBI121-GFP binary vectors under the control of the cauliflower mosaic virus $35 \mathrm{~S}$ promoter (CaMV35S). Subsequently, the pPBI121-EGPh-GFP plasmid was transferred into the competent cells of A. tumefaciens EHA105 using the freeze-thaw method (Hoekema et al. 1983). Then, the transformation of A. thaliana was performed by the floral-dip method (Bechtold and Pelletier 1998).

\section{Isolation and phenotype analysis of transgenic A. thaliana}

Transgenic T1 plants were selected on half-strength Murashige and Skoog medium with $50 \mathrm{mg} / \mathrm{L}$ Kanamycin. The Kan-resistant plants were transferred into soil and their morphology was observed throughout the development. The transformation of pPBI121EGPh-GFP into transgenic A. thaliana was confirmed by polymerase chain reaction (PCR). The total genomic DNA was isolated from the leaves of the transgenic plants using a Takara DNAiso reagent kit (Code No: 9770Q, TaKaRa, Dalian, China).

\section{Cellulase activity assay}

The total soluble proteins (TSP) were extracted from the leaf tissues of transgenic and wild type $A$. thaliana using the modified method (Thomas et al. 2001; Mei et al. 2009). Briefly, $600 \mathrm{mg}$ of fresh leaf tissue was ground into powder with liquid nitrogen. Then, 1.8 $\mathrm{mL}$ grinding buffer $\left(50 \mathrm{mmol} \mathrm{\textrm {L } ^ { - 1 }}\right.$ of sodium acetate, $10 \mathrm{mmol} \mathrm{L}^{-1}$ of ethylenediaminetetraacetic acid, and a $\mathrm{pH}$ of 5.0) were added and mixed thoroughly, and then the mixture was centrifuged at $20,000 \mathrm{~g}$ at $4{ }^{\circ} \mathrm{C}$ for $20 \mathrm{~min}$. The supernatant was precipitated using $70 \%$ saturated ammonium sulfate, and centrifuged at $20,000 \mathrm{~g}$ at $4{ }^{\circ} \mathrm{C}$ 
for $10 \mathrm{~min}$. The subsequent pellet was re-suspended with a $30 \mu \mathrm{L}$ grinding buffer. The extracts were quantified following the Bradford method using a standard curve generated from bovine serum albumin. The activities of heterologous EGPh to convert cellulose into glucose was assessed by measuring the reaction of TSP extracted from the leaves of transgenic and wild type A. thaliana with the soluble sodium carboxymethyl cellulose (CMC) (Sigma) or the insoluble microcrystalline cellulose Avicel (Analtech) as substrates. Briefly, $2 \mu \mathrm{L}$ TSP, $100 \mu \mathrm{L} \mathrm{1 \%}(\mathrm{wt} / \mathrm{mL}) \mathrm{CMC}$, or $1 \%$ Avicel was added in $98 \mu \mathrm{L}$ of 100 $\mathrm{mm}$ acetate buffer ( $\mathrm{pH}$ 5.6). The mixture was incubated with agitation at $80{ }^{\circ} \mathrm{C}$ for $10 \mathrm{~min}$ and cooled down in ice water (Hiromi et al. 1963). The total reducing sugar was determined using the modified Somogi-Nelson method (Lever et al. 1973). The reaction was terminated by adding $200 \mu \mathrm{L}$ of $0.5 \mathrm{M} \mathrm{NaOH}$. After the addition of $800 \mu \mathrm{L}$ 4-hydroxybenzoic acid hydrazide (PAHBAH) and being boiled for $10 \mathrm{~min}$ and then cooled down in ice water, the released reducing sugar was spectrophotometrically quantified at $420 \mathrm{~nm}$ and compared with the glucose standard curves. One unit of cellulase activity was defined as the amount of enzyme that catalyzed the releasing of $1 \mu \mathrm{mol}$ reducing sugar per minute.

\section{Subcellular localization analysis}

The subcellular localization of EGPh was predicted based on the identification of signal peptide sequences by ProtComp v.9.0 (Softberry, Inc., NY, USA) by Psort (Computational Biology Research Center, Tokyo, Japan). To determine the subcellular localization of the recombinant EGPh, the transient expression of EGPh-GFP in onion epidermal cells was analyzed. The constructs pPBI121-EGPh-GFP and pPBI121-GFP were transformed into onion (Allium cepa) epidermal cells mediated by A. tumefaciens EHA105 as described by Sun et al. (2007). Transformed cells were put in $10 \%$ sucrose for plasmolyzing. Green fluorescent protein was visualized using the inverted epifluorescence microscope (AxioVert.A1; Carl-Zeiss, Oberkochen, Germany). The images were captured on an Axio Cam IC Zeiss Camera (Oberkochen, Germany) using ZEN lite 2012 software (AxioVert.A1; Carl-Zeiss, Oberkochen, Germany).

\section{RESULTS AND DISCUSSION}

Codon optimization, gene synthesis, and the construction of plant expression vector

The codons of the EGPh gene were optimized by the OptimumGene ${ }^{\mathrm{TM}}$ algorithms (Genscript, Nanjing, China) according to the codon bias in S. bicolor. The variety of parameters critical to the efficiency of gene expression were optimized, codon adaptation index (CAI ) was upgraded from 0.71 to 0.84 , the guanine and cytosine (GC) content was optimized from 39.85 to 47.65 to prolong the half-life of the mRNA, and the percentage of high frequency codons $(<90 \%)$ increased to $95 \%$ after optimization. The optimized sequence was submitted to the GenBank Centre with accession numbers of MH830298 and was chemically synthesized from GenScript Co., Ltd. (Nanjing, China) (Fig. 1). The construction of pPBI121-EGPh-GFP was confirmed by double digestion (Fig. 2a). The transformation of $A$. tumefaciens was confirmed by PCR with primer EGPh F-1 and EGPh $\mathrm{R}$ (Table 1), in which the predicted $400 \mathrm{bp}$ fragments were amplified (Fig. 2b).

Though plants are well suited to the production of industrial enzymes for biomass treatment, the most important factor is to ensure competitive production cost (Xue et al. 2003; Tremblay et al. 2010). The best way to achieve this is to boost expression (Nandi et al. 2005; Streatfield 2007).

Li et al. (2019). "Hyperthermostable endoglucanase," BioResources 14(2), 2812-2826. 


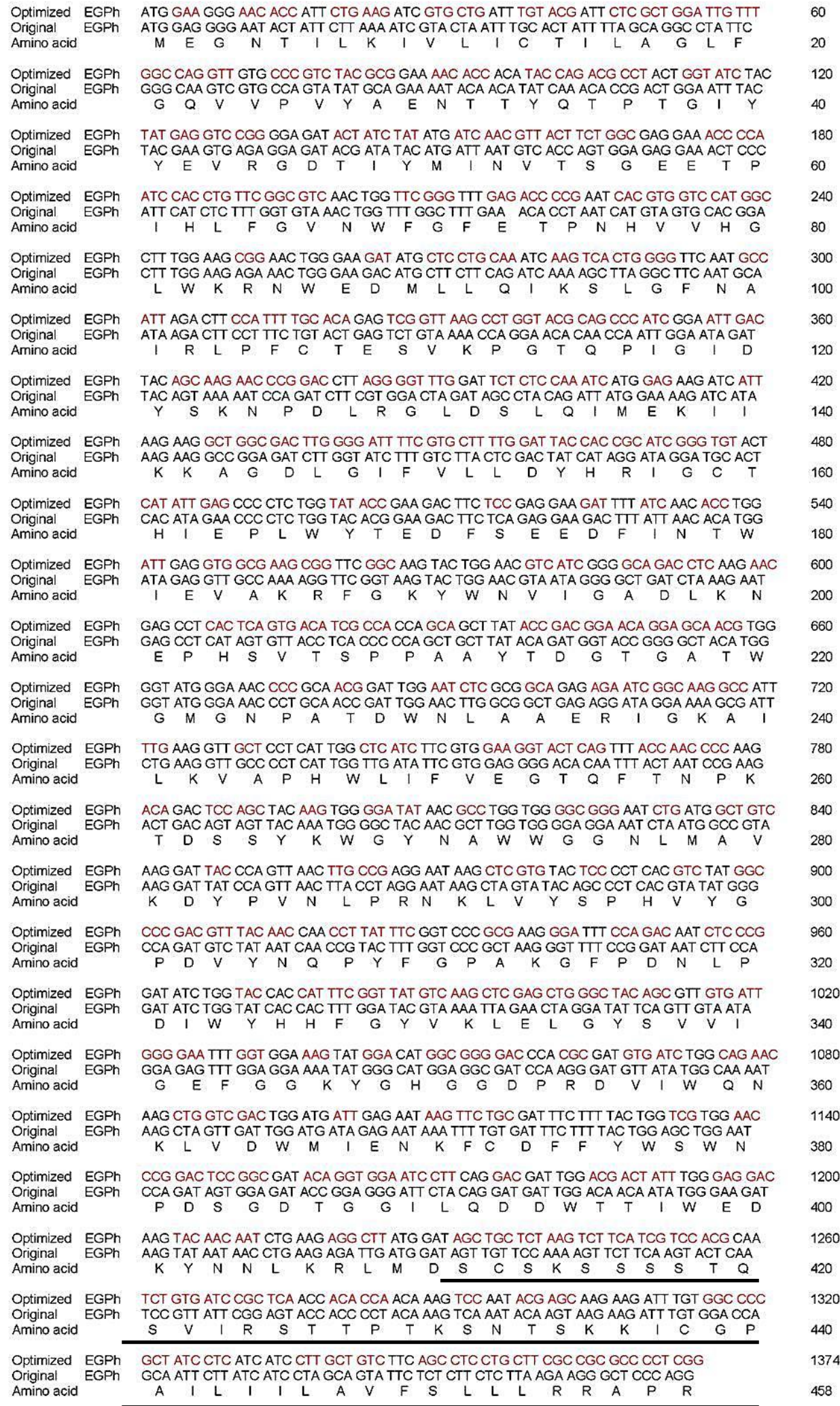

Fig. 1. The alignment of the original EGPh and codon optimized EGPh sequences based on Sorghum bicolor codon bias. The letters in red indicate the replaced codons; Optimized EGPh: codon optimized sequence of EGPh gene and Original EGPh: original sequence of EGPh gene. The predicted signal peptide-like sequence for membrane-binding is underlined. 


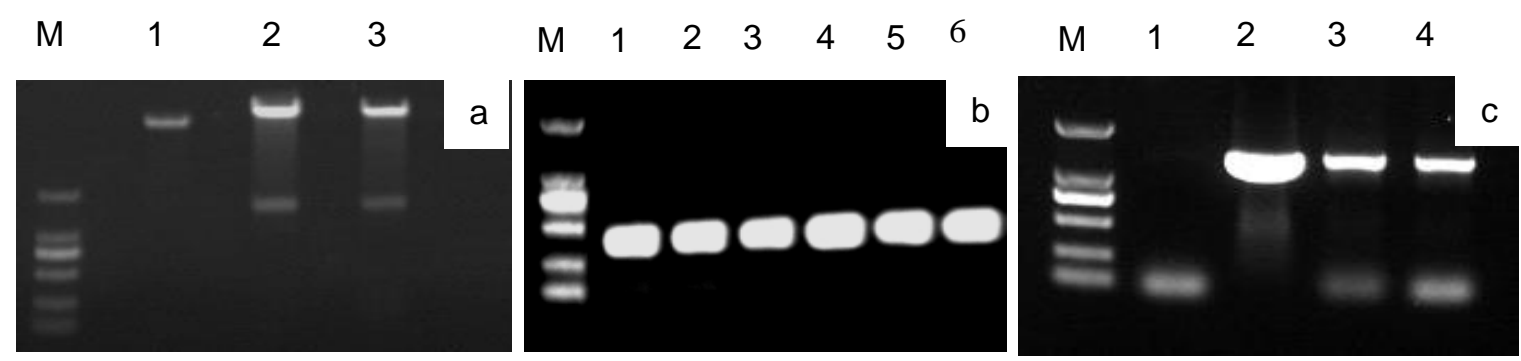

Fig. 2. The confirmation of pPBI121-EGPh, transgenic $A$. tumefaciens EHA105 and transgenic $A$. thaliana; M: DL2000 DNA marker; (a) The confirmation of pPBI121-EGPh vector; 1: pPBI121EGPh; 2 to 3: Double digestion of PBI121-EGPh by Xbal/Smal; (b) The confirmation of pPBI121EGPh in $A$. tumefaciens EHA105; 1 to 6: Clones of transformed $A$. tumefaciens EHA105; (c) 1: Wild-type $A$. thaliana (ecotype Columbia); 2: pPBI121-EGPh vector; 3 and 4: Transgenic $A$. thaliana

There are many strategies available to boost the expression of heterologous enzymes in plants, including the use of strong promoter, enhancer, codon optimization, 5' or 3' untranslated regions, and targeting to subcellular sites (Streatfield 2007; Desai et al. 2010). Among them, codon bias was increasingly realized to have profound impacts on the expression level of heterologous proteins (Kane 1995). After codon-optimization, the increases in the expression level of mammalian proteins was up to 5- to 15-fold (Gustafsson et al. 2004). The optimized coding sequence of the human cystatin $\mathrm{C}$ gene increased the expression and secretion of its protein by approximately 3- to 5-fold in yeast (Li et al. 2014). The protein expression of a mycotoxin zearalenone (ZEN) detoxifying gene was improved in $P$. pastoris through codon optimization (Xiang et al. 2016). Thus, to improve the expression level of EGPh in plants, this gene was optimized to codons favored by $S$. bicolor.

In addition, the Kozak sequence (CCA/GCCATGG) that extends from approximately position -6 to position +6 (the A in AUG is considered +1 ) was proposed as the most important context required for the efficient initiation of translation (Kozak 1987). Point mutations in the Kozak sequence can lead to a leaky scanning of the initiator codon AUG and reduced translation initiation over a 20-fold range (Kozak 1991, 1997). A 10fold higher luciferase activity was detected in the BmN4 cells transfected with the optimal consensus Kozak motif (Tatematsu et al. 2014). The 'most preferred' Kozak sequence in plants was reported as a 4-fold improvement of translation of a chitinase protein (Taylor $e t$ al. 1987). Thus, to improve the translation efficiency, the authors added an ACCACC Kozak consensus motif immediately preceding the ATG codon of the optimized sequence of EGPh. Moreover, the CaMV35S promoter was used in this study, which is a commonly used promoter of dicotyledonous plants that can enhance the transcription of heterologous genes more than specific promoters.

\section{The phenotype of transgenic A. thaliana}

The transgenic $A$. thaliana was confirmed by PCR with primer EGPh R and EGPh F-2 (Fig. 2c, Table 1), in which the predicted $1400 \mathrm{bp}$ fragments were amplified. The 35S::EGPh transgenic A. thaliana were healthy and developed normally compared with the wild type, which indicated that the expression of the exogenous gene EGPh had no negative effect on the growth and development of $A$. thaliana (Fig. 3). 
Table 1. Primers Used in This Research

\begin{tabular}{|c|c|}
\hline Primer Name & Sequence \\
\hline EGPh R & AAG GAT GAT GAG GAT AGC G \\
\hline EGPh F-1 & CGA AGG GAT TTC CAG ACA \\
\hline EGPh F-2 & TCT AGA CCA CCA TGG AAC AC \\
\hline
\end{tabular}

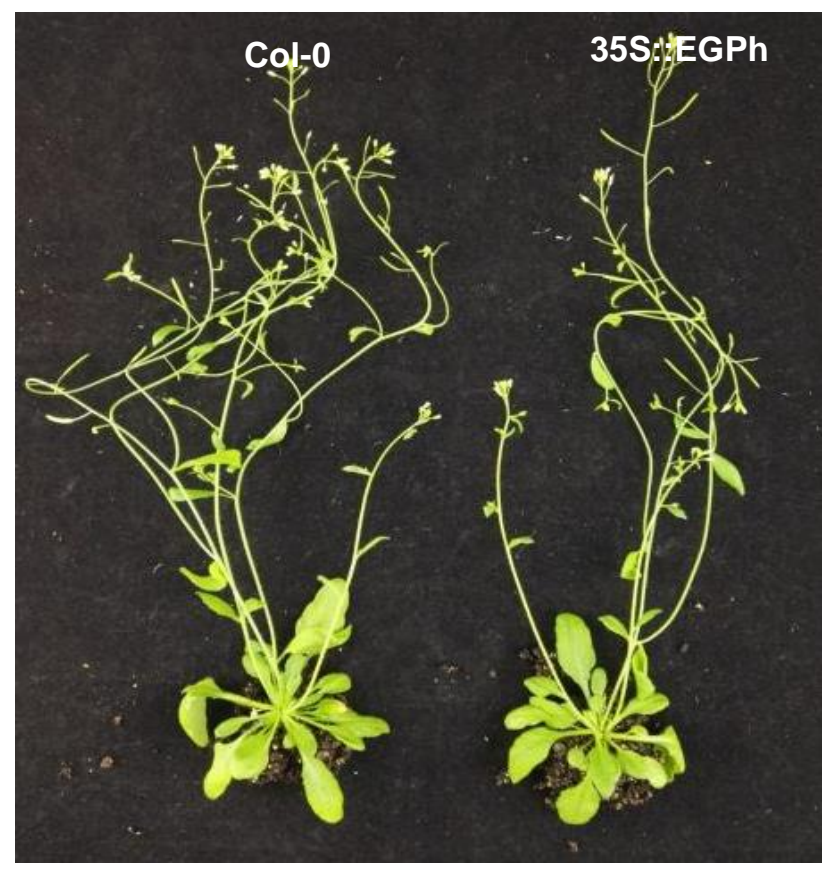

Fig. 3. The phenotype of transgenic $A$. thaliana; Col-0: wild type $A$. thaliana (ecotype Columbia) 35S::EGPh: transgenic $A$. thaliana

Thus far, the hyperthermostable cellulases have been highly expressed in Arabidopsis, rice, tobacco, potato, barley, corn, and other plants, with no deleterious effects to the growth and development and no obvious change in plant phenotypes (Ziegler et al. 2000; Ziegelhoffer et al. 2001; Devaiah et al. 2013). In this research, the 35S::EGPh transgenic $A$. thaliana were healthy and developed normally compared with the wild type, which indicated that the expression of the exogenous gene EGPh had no negative effect on the growth and development of A. thaliana. This may have been due to the limited activity of thermophilic cellulase at room temperatures in plants or the lack of direct access of thermophilic cellulase to the cellulose in the plant wall, which is present as a compact mixture together with lignin and hemicellulose (Sticklen 2006). However, this result was inconsistent with the expression of EGPh gene in tobacco chloroplast, in which transgenic plants demonstrated pale-green color and a slower growth rate than the wild-type plants (Nakahira 2013). Therefore, changes in the components and construction of the cell wall of transgenic $A$. thaliana were analyzed next to illustrate the effects of heterologous EGPh on plant cell wall recalcitrance.

The activity of heterologous EGPh in A. thaliana

The TSP were extracted from the leaf tissues of transgenic and wild type $A$. thaliana. With these three strategies applied (condon optimization, Kozak sequence, CaMV35S promoter), the activities of EGPh in transgenic A. thaliana were up to 111.69 $\pm 6.53 \mathrm{U} \mathrm{mg}^{-1}$ and 13.35 $\pm 0.24 \mathrm{U} \mathrm{mg}^{-1} \mathrm{TSP}$ against CMC and Avicel (Fig. 4), higher 
than EGPh expressed in tobacco chloroplast (20.5U mg-1 TSP against CMC) (Nakahira 2013) and almost comparable with cellulase produced by microbial production system (220 $\mathrm{U} \mathrm{mg}^{-1} \mathrm{TSP}$ against CMC) (Bao et al. 2011; Ul Haq et al. 2015).

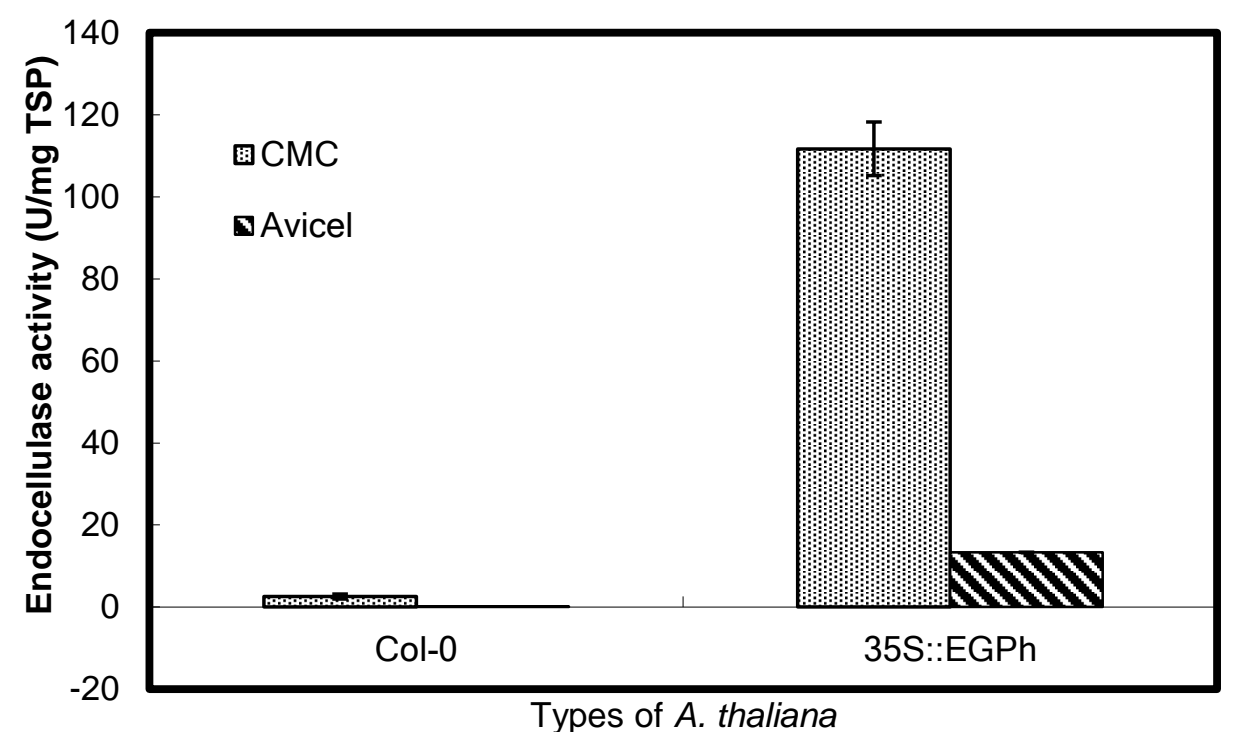

Fig. 4. The endocellulase activity of EGPh in transgenic $A$. thaliana; Col-0: wild-type $A$. thaliana (ecotype Columbia) 35S::EGPh: transgenic $A$. thaliana; CMC: The soluble sodium CMC was used as substrate; Avicel: The insoluble microcrystalline cellulose Avicel was used as substrate

As a highly promising application prospect both in the biofuel and textile industry for its hyperthermostability and capability of hydrolyzing crystalline cellulose, EGPh has been extensively studied in recent years. The high activities of EGPh in transgenic $A$. thaliana implied that it is an ideal candidate for the economic production of cellulases in biomass crops. The results also demonstrated that codon optimization, Kozak sequences, and a CaMV35S promoter do help in the active, high-level expression of $P$. horikoshii $\mathrm{EGPh}$ in A. thaliana and must be factors considered in the expression of heterologous enzymes in plants. However, although the activities of recombinant EGPh in transgenic $A$. thaliana are relatively high, it is still remarkably lower compared to the amount required for complete biomass degradation. To further increase the accumulation of EGPh, other regulation strategies need to be applied. For instance, enhancer and untranslated regions play important roles in improving the accumulation of heterologous cellulase in plants (Ziegler et al. 2000). Expressing only the catalytic domains was reported to greatly increase the amounts of heterologous enzymes (Ziegelhoffer et al. 2001).

\section{Compartmentalization of heterologous EGPh in plants}

The authors predicted the potential subcellular localization of the EGPh using ProtComp v.9.0 and WoLF PSORT. The ProtComp v.9.0 predicted that EGPh may be an extracellular (secreted) protein with a low score of 2.4. The WoLF PSORT predicted that it might localize in the plasma membrane. The subcellular localization of the EGPh protein was then analyzed in transient expression assays on the epidermal cells of onion. The EGPh-GFP protein was expressed on the plasma membrane and cell wall (Figs. $5 \mathrm{~g}$ through 5o), while the GFP protein was observed in cytosol (Figs. 5a through 5f). 
PI
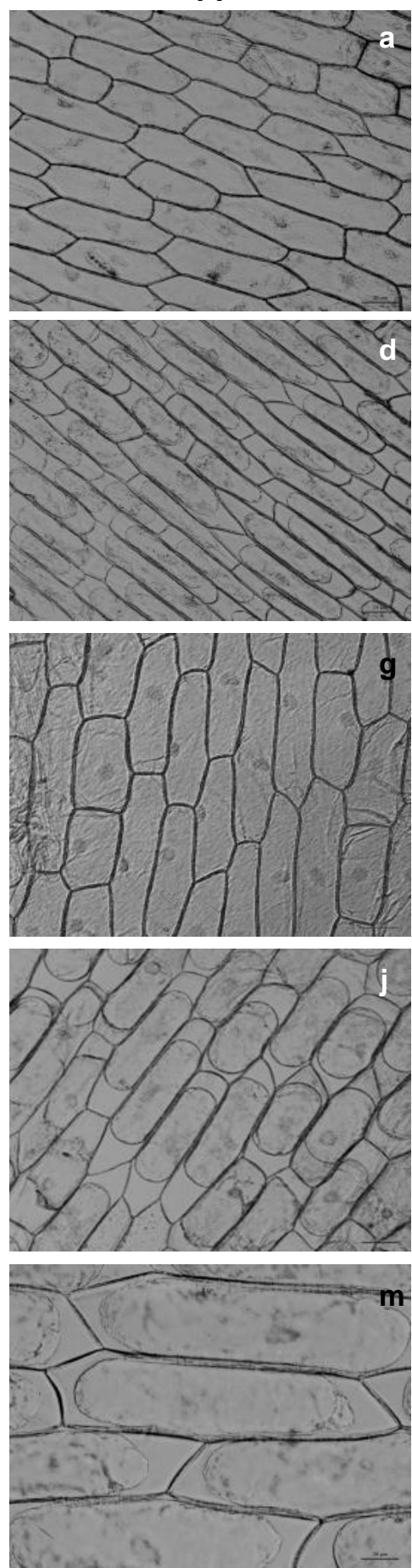

GFP
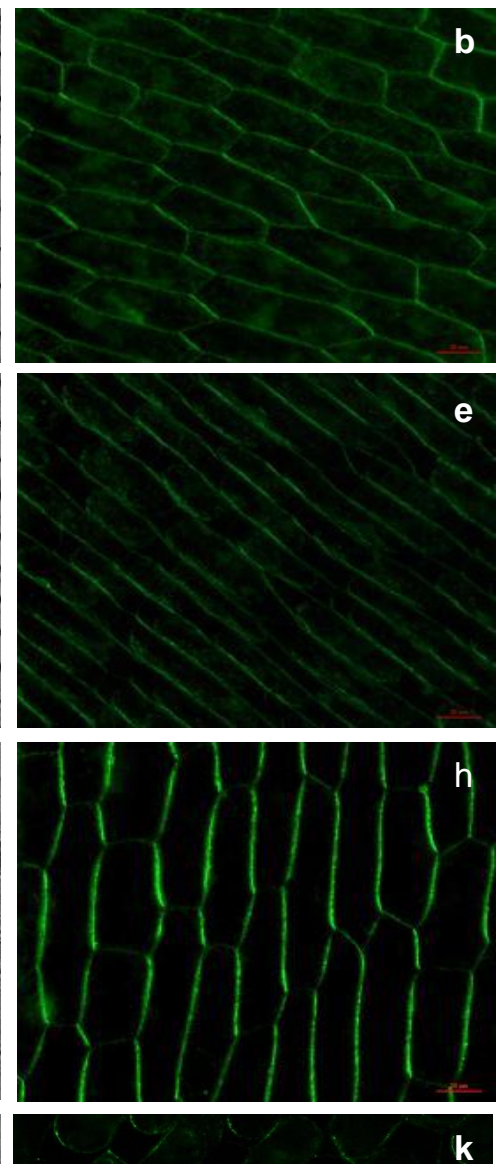

k

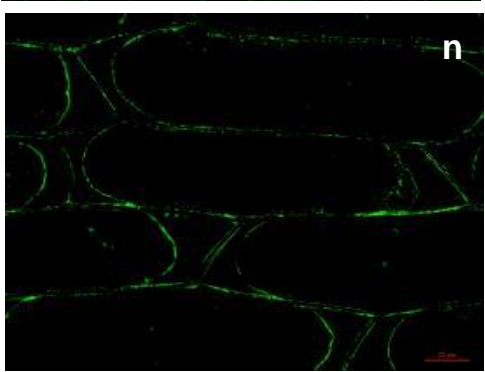

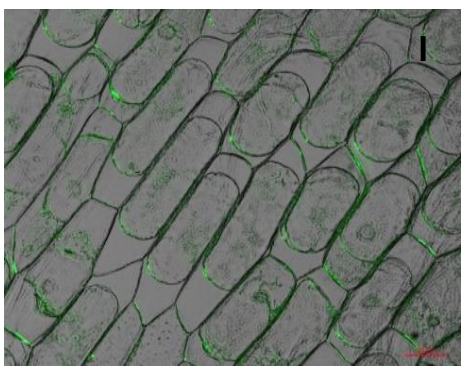

Merged
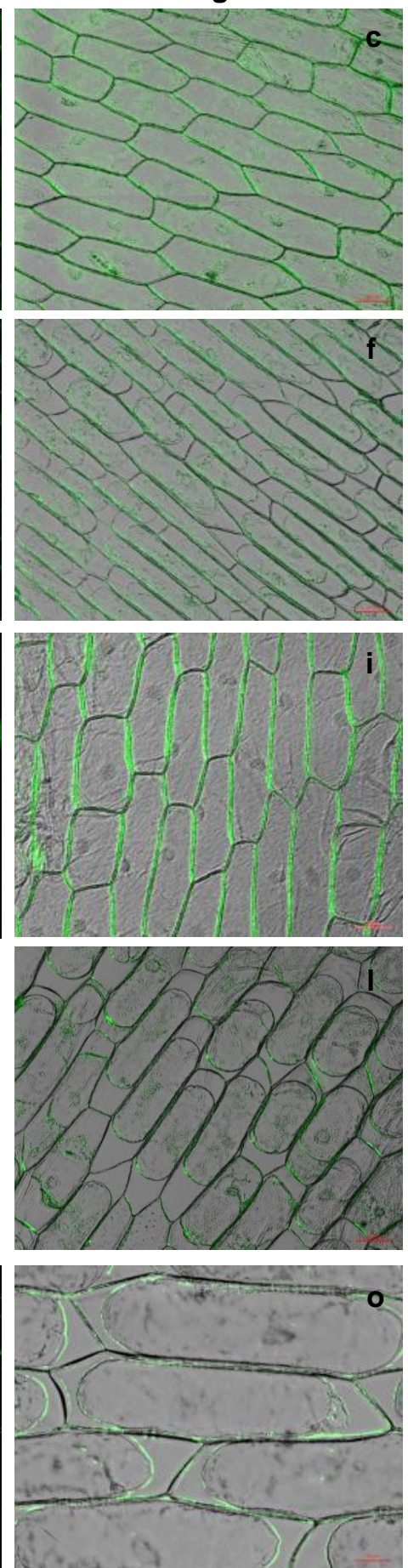

Fig. 5. The subcellular localization of EGPh-GFP fusion protein pPBI121-EGPh-GFP and pPBI121EGPh-GFP and pPBI121-GFP vectors were introduced into onion epidermal cells. Time course images were obtained by an inverted epifluorescence microscope after agroinfiltration. The onion cells were plasmolyzed in $10 \%(\mathrm{~g} / \mathrm{v})$ sucrose. Dark-field, bright-field, and merged images are shown; c, f, i, l, o were merged images of a+b, d+e, $g+h, j+k, m+n$, respectively; Green fluorescent protein of control GFP before (a through $\mathrm{c}$ ) and after plasmolysis ( $d$ through $\mathrm{f}$ ), which appeared in cytosol; Green fluorescent protein of EGPh-GFP before ( $g$ through i), after plasmolysis ( $j$ through $\mathrm{f}$ ) and under higher magnification ( $\mathrm{m}$ through $\mathrm{o}$ ), which appeared on the plasma membrane and cell wall; The scale bars equal $20 \mu \mathrm{m}$. 
Compartmentalization plays an important role on the expression level and activity of recombinant cellulases. It was reported that the activity and accumulation of heterologous cellulase were highest in apoplasts and chloroplasts (Dai et al. 2005; Jung et al. 2013). The endoglucanase Cel5A from Thermotoga maritima was expressed in tobacco targeted to different subcellular compartments, which showed no enzyme accumulation when it was targeted to cytosol but produced the highest endoglucanase activity when targeted to chloroplast (Mahadevan et al. 2011). However, it was not evident which subcellular compartments were best for any particular protein (Hood and Requesens 2014). The endoglucanase $\mathrm{E}_{1}$ from A. cellulolyticus showed a low expression in plant cytosol (Ziegelhoffer et al. 1999). However, when the enzyme was localized to endoplasmic reticulum, cell wall, or vacuole, the yield was up to $16 \%$ of TSP (Hood et al. 2007). The EGPh was predicted as a secreted and membrane-binding enzyme in $P$. horikoshii for its membrane-binding signal peptide-like sequence at the $C$ terminal (Fig. 1) (Kashima et al. 2005). Thus, this study analyzed the subcellular localization of EGPh in plants. The subcellular location of EGPh in onion epidermal cells showed a similar result, with the cellulase located on the cell wall and membrane. However, other plant signal peptides should be added to the EGPh to assess the effects caused by differential targeting sites, like ER, chloroplast, apoplast, vacuole, and mitochondria to gain higher accumulation and activity of EGPh.

\section{CONCLUSIONS}

The coding sequence of the hyperthermostable endocellulase EGPh gene from $P$. horikoshii was expressed in Arabidopsis thaliana under the control of a CaMV35S promoter after codon optimization. The results showed that:

1. Condon optimization and Kozak sequence are effective strategies for high-level expression of EGPh in plants.

2. The expression of EGPh showed no deleterious effects to the growth and development of transgenic A. thaliana.

3. The heterologous EGPh showed relatively high activities to hydrolyze Avicel and CMC.

4. Lastly, EGPh is a promising candidate for the commercial production of cellulase in biomass crops.

\section{ACKNOWLEDGMENTS}

The authors are grateful for the support of the startup support of Jiangsu University (11JDG076), the Natural Science Foundation of the Jiangsu Province (BK20160508), the National Natural Science Foundation of China (31671754/31601380), and the Priority Academic Program Development of Jiangsu Higher Education Institutions (PAPD). 


\section{REFERENCES CITED}

Ando, S., Ishida, H., Kosugi, Y., and Ishikawa, K. (2002). "Hyperthermostable endoglucanase from Pyrococcus horikoshii," Appl. Environ. Microb. 68(1), 430-433. DOI: 10.1128/AEM.68.1.430-433.2002

Bao, L., Huang, Q., Chang, L., Zhou, J., and Lu, H. (2011). "Screening and characterization of a cellulase with endocellulase and exocellulase activity from yak rumen metagenome," J. Mol. Catal. B-Enzym. 73(1), 104-110. DOI: 10.1016/j.molcatb.2011.08.006

Bechtold, N., and Pelletier, G. (1998). "In planta Agrobacterium-mediated transformation of adult Arabidopsis thaliana plants by vacuum infiltration," in: Methods in Molecular Biology, Volume 82, J. M. Martinez-Zapater and J. Salinas (eds), Humana Press, Totowa, USA, pp. 259-266. DOI: 10.1385/0-89603-391-0:259

Biswas, G. C. G., Ransom, C., and Sticklen, M. (2006). "Expression of biologically active Acidothermus cellulolyticus endoglucanase in transgenic maize plants," Plant Sci. 171(5), 617-623. DOI: 10.1016/j.plantsci.2006.06.004

Chen, P., and Peng, L. C. (2014). "The diversity of lignocellulosic biomass resources and their evaluation for use as biofuels and chemicals," in: Biological Conversion of Biomass for Fuels and Chemicals, J. Z. Sun, S. H. Ding, and J. Doran-Peterson (eds.), RSC Publishing, Cambridge, England, pp. 83-109. DOI: 10.1039/9781849734738-FP001

Chou, H. L., Dai, Z., Hsieh, C. W., and Ku, M. S. (2011). "High level expression of Acidothermus cellulolyticus beta-1,4-endoglucanase in transgenic rice enhances the hydrolysis of its straw by cultured cow gastric fluid," Biotechnol. Biofuels 4, 58-70. DOI: 10.1186/1754-6834-4-58

Dai, Z. Y., Hooker, B. S., Quesenberry, R. D., and Thomas, S. R. (2005). "Optimization of Acidothermus cellulolyticus endoglucanase (E1) production in transgenic tobacco plants by transcriptional, post-transcription and post-translational modification," Transgenic Res. 14(5), 627-643. DOI: 10.1007/s11248-005-5695-5

Devaiah, S. P., Requesens, D. V., Chang, Y. K., Hood, K. R., Flory, A., Howard, J. A., and Hood, E. E. (2013). "Heterologous expression of cellobiohydrolase II (Cel6A) in maize endosperm," Transgenic Research 22(3), 477-488. DOI: 10.1007/s11248-0129659-2

Desai, P. N., Shrivastava, N., and Padh, H. (2010). "Production of heterologous proteins in plants: Strategies for optimal expression," Biotechnol. Adv. 28(4), 427-435. DOI: 10.1016/j.biotechadv.2010.01.005

Duchesne, L. C., and Larson, D. W. (1989). "Cellulose and the evolution of plant life," Bioscience 39(4), 238-241. DOI: 10.2307/1311160

Gray, B. N., Ahner, B. A., and Hanson, M. R. (2008). "High-level bacterial cellulase accumulation in chloroplast-transformed tobacco mediated by downstream box fusions," Biotechnol. Bioeng. 102(4), 1045-1054. DOI: 10.1002/bit.22156

Gray, B. N., Bougri, O., Carlson, A. R., Meissner, J., Pan, S. H., Parker, M. H., Zhang, D. C., Samoylov, V., Ekborg, N. A., and Raab, M. R. (2011). "Global and grain-specific accumulation of glycoside hydrolase family 10 xylanases in transgenic mainze (Zea mays)," Plant Biotechnol. J. 9(9), 1100-1108. DOI: 10.1111/j.1467-

7652.2011.00632.x 
Gustafsson, C., Govindarajan, S., and Minshull, J. (2004). "Codon bias and heterologous protein expression," Trends Biotechnol. 22(7), 346-353. DOI:

10.1016/j.tibtech.2004.04.006

Haki, G. D., and Rakshit, S. K. (2003). "Developments in industrially important thermostable enzymes: A review," Bioresource Technol. 89(1), 17-34. DOI: 10.1016/S0960-8524(03)00033-6

Hiromi, K., Takahashi, Y., and Ono, S. (1963). "Kinetics of hydrolytic reaction catalyzed by crystalline bacterial $\alpha$-amylase. III. The influence of temperature," B. Chem. Soc. Jpn. 36(5), 563-569. DOI: 10.1246/bcsj.36.563

Hoekema, A., Hirsch, P. R., Hooykaas, P. J. J., and Schilperoort, R. A. (1983). “A binary plant vector strategy based on separation of vir- and T-region of the Agrobacterium tumefaciens Ti-plasmid," Nature 303(5913), 179-180. DOI: 10.1038/303179a0

Hood, E. E., Love, R., Lane, J., Bray, J., Clough, R., Pappu, K., Drees, C., Hood, K. R., Yoon, S., Ahmad, A., et al. (2007). "Subcellular targeting is a key condition for highlevel accumulation of cellulase protein in transgenic maize seed," Plant Biotechnol. J. 5(6), 709-719. DOI: 10.1111/j.1467-7652.2007.00275.x

Hood, E. E., and Requesens, D. V. (2014). “Commercial plant-produced recombinant cellulases for biomass conversion," in: Commercial Plant-Produced Recombinant Protein Products, J. A. Howard and E. E. Hood (eds.), Springer, Berlin, Germany. DOI: $10.1007 / 978-3-662-43836-7 \_12$

Jiang, X. R., and Li, W. L. (2009). "Research progress in genetic engineering for cellulosic ethanol,” China Bioengineering Journal 2009(7), 127-133. DOI: 10.13523/j.cb.20090721

Jung, S., Lee, D. S., Kim, Y. O., Joshi, C. P., and Bae, H. J. (2013). "Improved recombinant cellulase expression in chloroplast of tobacco through promoter engineering and 5'amplification promoting sequence," Plant Mol. Biol. 83(4-5), 317328. DOI: $10.1007 / \mathrm{s} 11103-013-0088-2$

Kane, J. F. (1995). "Effects of rare codon clusters on high-level expression of heterologous proteins in Escherichia coli," Curr. Opin. Biotechn. 6(5), 494-500. DOI: 10.1016/0958-1669(95)80082-4

Kashima, Y., Mori, K., Fukada, H., and Ishikawa, K. (2005). "Analysis of the function of a hyperthermophilic endoglucanase from Pyrococcus horikoshii that hydrolyzes crystalline cellulose," Extremophiles 9(1), 37-43. DOI: 10.1007/s00792-004-0418-z

Kim, H. W., and Ishikawa, K. (2010a). "Complete saccharification of cellulose at high temperature using endocellulase and $\beta$-glucosidase from Pyrococcus sp.," J. Microbiol. Biotechn. 20(5), 889-892. DOI: 10.4014/jmb.0912.12020

Kim, H. W., and Ishikawa, K. (2010b). "Structure of hyperthermophilic endoglucanase from Pyrococcus horikoshii," Proteins 78(2), 496-500. DOI: 10.1002/prot.22602

Kim, H. W., and Ishikawa, K. (2013). "The role of disulfide bond in hyperthermophilic endocellulase," Extremophiles 17(4), 593-599. DOI: 10.1007/s00792-013-0542-8

Kishishita, S., Fujii, T., and Ishikawa, K. (2015). "Heterologous expression of hyperthermophilic cellulases of archaea Pyrococcus sp. by fungus Talaromyces cellulolyticus," J. Ind. Microbiol. Biot. 42(1), 137-141. DOI: 10.1007/s10295-0141532-2

Klose, H., Günl, M., Usadel, B., Fischer, R., and Commandeur, U. (2013). "Ethanol inducible expression of a mesophilic cellulase avoids adverse effects on plant development," Biotechnol. Biofuels 6(1), 53-62. DOI: 10.1186/1754-6834-6-53 
Kozak, M. (1987). “An analysis of 5' -no coding sequences from 699 vertebrate messenger RNAs," Nucleic Acids Res. 15(20), 8125-8148. DOI: 10.1093/nar/15.20.8125

Kozak, M. (1991). "Effects of long 5' leader sequences on initiation by eukaryotic ribosomes in vitro," Gene Expression 1(2), 117-125.

Kozak, M. (1997). "Recognition of AUG and alternative initiator codons is augmented by $\mathrm{G}$ in position +4 but is not generally affected by the nucleotides in positions +5 and +6," Embo J. 16(9), 2482-2492. DOI: 10.1093/emboj/16.9.2482

Lever, M., Powell, J. C., Killip, M., and Small, C. W. (1973). “A comparison of 4hydroxy-benzoic acid hydrazide (PAHBAH) with other reagents for the determination of glucose," J. Lab. Clin. Med. 82(4), 649-655.

Li, Y. M., Li, D. J., Xu, X. J., Cui, M. M., Zhen, H. H., and Wang, Q. (2014). "Effect of codon optimization on expression levels of human cystatin C in Pichia pastoris," Genet. Mol. Res. 13(3), 4990-5000. DOI: 10.4238/2014.July.4.14

Mahadevan, S. A., Wi, S. G., Kim, Y. O., Lee, K. H., and Bae, H. J. (2011). "In planta differential targeting analysis of Thermotoga maritima Cel5A and CBM6-engineered Cel5A for autohydrolysis," Transgenic Res. 20(4), 877-886. DOI: 10.1007/s11248010-9464-8

Mei, C., Park, C. H., Sabzikar, R., Qi, C., Ransom, C., and Sticklen, M. B. (2009). "Green tissue-specific production of a microbial endo-cellulase in maize (Zea mays L.) endoplasmic-reticulum and mitochondria converts cellulose into fermentable sugars," J. Chem. Technol. Biot. 84(5), 689-695. DOI: 10.1002/jctb.2100

Menkhaus, T. J., Bai, Y., Zhang, Z., Nikolov, L., and Glatz, C. E. (2004). "Considerations for the recovery of recombinant proteins from plants," Biotechnol. Progr. 20(4), 1001-1014. DOI: 10.1021/bp040011m

Nakahira, Y., Ishikawa, K., Tanaka, K., Tozawa, Y., and Shiina, T. (2013). "Overproduction of hyperthermostable $\beta$-1,4-endoglucanase from the Archaeon Pyrococcus horikoshii by tobacco chloroplast engineering," Biosci.Biotech.Biochem. 77(10), 2140-2143. DOI: 10.1271/bbb.130413

Nandi, S., Yalda, D., Lu, S., Nikolov, Z., Misaki, R., Fujiyama, K., and Huang, N. (2005). "Process development and economic evaluation of recombinant human lactoferrin expressed in rice grain," Transgenic Res. 14(3), 237-249. DOI: $10.1007 / \mathrm{s} 11248-004-8120-6$

Pauly, M., and Keegstra, K. (2008). "Cell-wall carbohydrates and their modification as a resource for biofuels," Plant J. 54(4), 559-568. DOI: 10.1111/j.1365313X.2008.03463.X

Phitsuwan, P., Laohakunjit, N., Kerdchoechuen, O., Kyu, K. L., and Ratanakhanokchai, K. (2012). "Present and potential applications of cellulases in agriculture, biotechnology, and bioenergy," Folia Microbiol. 58(2), 163-167. DOI: 10.1007/s12223-012-0184-8

Poorter, H., and Villar, R. (1997). "The fate of acquired carbon in plants: Chemical composition and construction costs," in: Plant Resource Allocation, F. A. Bazzaz and J. Grace (eds.), Academic Press, San Diego, USA, pp. 39-72. DOI: 10.1016/B978012083490-7/50003-7

Ransom, C., Balan, V., Biswas, G., Dale, B., Crockett, E., and Sticklen, M. (2007). "Heterologous Acidothermus cellulolyticus 1, 4- $\beta$-endoglucanase E1 produced within corn biomass converts corn stover into glucose," Appl. Biochem. Biotech. 137-140(112), 207-219. DOI: 10.1007/s12010-007-9053-3. 
Sharma, A. K., and Sharma, M. K. (2009). "Plants as bioreactors: Recent developments and emerging opportunities," Biotechnol. Adv. 27(6), 811-833. DOI: 10.1016/j.biotechadv.2009.06.004

Singh, J., Suhag, M., and Dhaka, A. (2015). "Augmented digestion of lignocellulose by steam explosion, acid and alkaline pretreatment methods: A review," Carbohyd. Polym. 117, 624-631. DOI: 10.1016/j.carbpol.2014.10.012

Sticklen, M. (2006). "Plant genetic engineering to improve biomass characteristics for biofuels," Curr. Opin. Biotech. 17(3), 315-319. DOI: 10.1016/j.copbio.2006.05.003

Streatfield, S. J. (2007). "Approaches to achieve high-level heterologous protein production in plants," Plant Biotechnol. J. 5(1), 2-15. DOI: 10.1111/j.14677652.2006.00216.x

Sun, W., Cao, Z. Y., Li, Y., Zhao, Y. X., and Zhang, H. (2007). "A simple and effective method for protein subcellular localization using Agrobacterium-mediated transformation of onion epidermal cells," Biologia 62(5), 529-532. DOI: 10.2478/s11756-007-0104-6

Tatematsu, K., Uchino, K., Sezutsu, H., and Tamura, T. (2014). "Effect of ATG initiation codon context motifs on the efficiency of translation of mRNA derived from exogenous genes in the transgenic silkworm, Bombyx mori," SpringerPlus 3, 136147. DOI: $10.1186 / 2193-1801-3-136$

Taylor, J. L., Jones, J. D. G., Sandler, S., Mueller, G. M., Bedbrook, J., and Dunsmuir, P. (1987). "Optimizing the expression of chimeric genes in plant cells," Mol. Gen. Genet. 210(3), 572-577. DOI: 10.1007/BF00327214

Tremblay, R., Wang, D., Jevnikar, A. M., and Ma, S. W. (2010). “Tobacco, a highly efficient green bioreactor for production of therapeutic proteins," Biotechnol. Adv. 28(2), 214-221. DOI: 10.1016/j.biotechadv.2009.11.008

Twyman, R. M., Stoger, E., Schillberg, S., Christou, P., and Fischer, R. (2003). "Molecular farming in plants: Host systems and expression technology," Trends Biotechnol. 21(12), 570-578. DOI: 10.1016/j.tibtech.2003.10.002

Ul Haq, I., Muneer, B., Hussain, Z., Khan, M. A., Afzal, S., Majeed, S., Akram, F., and Akmal, S. (2015). "Thermodynamic and saccharification analysis of cloned GH12 endo-1,4- $\beta$-glucanase from Thermotoga petrophila in a mesophilic host," Protein Peptide. Lett. 22(9), 785-794. DOI: 10.2174/0929866522666150630105035

Xue, G. P., Patel, M., Johnson, J. S., Smyth, D. J., and Vickers, C. E. (2003). "Selectable marker-free transgenic barley producing a high level of cellulase (1,4-beta-glucanase) in developing grains," Plant Cell Rep. 21(11), 1088-1094. DOI: 10.1007/s00299-0030627-4

Xiang, L., Wang, Q., Zhou, Y., Lin, L., Zhang, G., and Ma, Y. (2016). "High-level expression of a ZEN-detoxifying gene by codon optimization and biobrick in Pichia pastoris," Microbiol. Res. 193, 48-56. DOI: 10.1016/j.micres.2016.09.004

Yang, T. C., Legault, S., Kayiranga, E. A., Kumaran, J., Ishikawa, K., and Sung, W. L. (2012). "The N-terminal $\beta$-sheet of the hyperthermophilic endoglucanase from Pyrococcus horikoshii is critical for thermostability," Appl. Environ. Microb. 78(9), 3059-3067. DOI: 10.1128/AEM.07576-11

Ziegelhoffer, T., Raasch, J. A., and Austin-Phillips, S. (2001). "Dramatic effects of truncation and sub-cellular targeting on the accumulation of recombinant microbial cellulase in tobacco," Mol. Breeding. 8(2), 147-158. DOI: 10.1023/A:1013338312948

Ziegelhoffer, T., Will, J., and Austin-Phillips, S. (1999). "Expression of bacterial cellulase genes in transgenic alfalfa (Medicago sativa L.), potato (Solanum tuberosum 
L.) and tobacco (Nicotiana tabacum L.)," Mol. Breeding 5(4), 309-318. DOI: 10.1023/A:1009646830403

Ziegler, M. T., Thomas, S. R., and Danna, K. J. (2000) "Accumulation of a thermostable endo-1, 4- $\beta$-D-glucanase in the apoplast of Arabidopsis thaliana leaves," Mol.

Breeding 6(1), 37-46. DOI: 10.1023/A:1009667524690

Article submitted: November 8, 2018; Peer review completed: February 3, 2019; Revised version received: February 13, 2019; Accepted: February 14, 2019, Published: February 19, 2019.

DOI: 10.15376/biores.14.2.2812-2826 